original paper

doi: https://doi.org/10.5114/pq.2023.112272

\title{
Effect of myofascial trigger points release with shockwave therapy on shoulder hand syndrome in stroke patients
}

\author{
Lama Saad El-Din Mahmoud ${ }^{1}$, Shahesta Ahmed Osama², Lamis Ahmed Osama ${ }^{3}$ \\ ${ }^{1}$ Lecturer, Faculty of Physical Therapy, Department of Neuromuscular Disorder and Its Surgery, \\ October 6 University, Egypt \\ ${ }^{2}$ Faculty of Physical Therapy, Department of Musculoskeletal Disorders and Its Surgery, October 6 \\ University, Egypt \\ ${ }^{3}$ Lecturer, Faculty of Physical Therapy, Department of Physical Therapy For Internal Diseases, \\ October 6 University, Egypt
}

Correspondence address: Lama Saad El-Din Mahmoud, Faculty of Physical Therapy, Department of Neuromuscular Disorder and Its Surgery, October 6 University, Egypt

e-mail: lama.elsedawy.pt@o6u.edu.eg, https://orcid.org/0000-0003-4914-2141

\begin{abstract}
Introduction. To investigate the influence of Myofascial Trigger Points (MTrPs) release combined with shockwave therapy on pain and functions of the upper extremity with shoulder hand syndrome (SHS) in stroke patients with diabetic neuropathy.

Methods. Two groups of thirty stroke patients, divided equally into, the study group: which received MTrPs release with shockwave therapy and conventional physical therapy program, while the control group: received the conventional physical therapy program. All the patients were evaluated pre-and post-intervention by the severity score of the Complex Regional Pain Syndrome (CRPS), Motor Evaluation Scale Upper Extremity Stroke Patients (MESUPES), the figure of eight test for hand swelling, and the Visual Analogue Scale for pain (VAS-P).

Results. highly significant improvement of affected upper extremity functions, with a significant reduction of SHS symptoms, swelling, and pain of the study group compared to the control group (p $<0.05)$, also there was a negative significant correlation between MESUPES- all-out score and VAS-P.
\end{abstract}

Conclusions. The combination of both MTrPs release with shockwave therapy had a significant improvement effect on upper extremity function and a significant reduction of both SHS symptoms and pain in stroke patients with diabetic neuropathy, which leads to improvement in stroke patients' functional rehabilitation.

Key words: stroke; myofascial trigger points release; shockwave; shoulder hand syndrome; diabetic neuropathy.

\section{Introduction}

Stroke is typical cerebrum damage due to the rupture or impediment of cerebrovascular structures [1]. Among stroke patients, shoulder hand syndrome (SHS) is very common, as both the spasticity and paresis of the shoulder muscles are considered the principal hazard factors, with the incidence rate going from $12 \%$ to $49 \%$ [2]. Reflex sympathetic dystrophy or complex regional pain syndrome (CRPS) type I, likewise alluded to as post-stroke SHS [3], is an endless neurological issue including the extremities described by pain, swelling, motor dysfunctions, and vasomotor unsteadiness [4].

Post-stroke neurological CRPS problems in the form of SHS are generally characterized by painful shoulder and wrist with relatively spared elbow [5], the damage actuated the interaction between sensory fibers and postganglionic efferent sympathetic axons that could be the premise of SHS [6]. The SHS creates nearly from one to six months after stroke as it started by shoulder pain 
and loss of range of motion (ROM) trailed by the warmth of the distal part of the upper extremity (UE) [7-8]. Various examinations stated that CRPS is also one of the complications of the musculoskeletal system in Diabetes mellitus (DM) patients [9]. The DM is greatly associated with CRPS, as in stroke patients with uncontrolled hyperglycemia diabetes it could influence the CRPS events, due to the expanded rates of glycosylated hemoglobin (HbA1c), so CRPS incidence expanded also [10].

In spastic stroke patients, the myofascial trigger point (MTrPs) is characterized by the existence of a nodule in a tight band of skeletal muscle during palpation [11]. The spontaneous pain is represented in the active MTrP, while the latent MTrP is not related to spontaneous pain but rather evokes localized pain during pressure on it, both MTrPs can be related to ROM limitation and muscle weakness or dysfunctions [12]. Myofascial trigger point release therapy intended to discharge the restrictions and barriers inside the more profound layers of fascia, trailed by static stretching to affect the spastic muscles [11], as the underlying-mechanism manages neuro-reflexive change with the manual pressure during Myofascial release (MFR), which could lead to stimulation of afferent through the receptors, that gives reaction by central processing at the spinal cord and cortical levels, thus it brings about inhibition of efferent so promotes relaxation [1], consequently permitting expanded ROM, flexibility, circulation and pain reduction [12-13].

The painful shoulder after stroke could be treated by the Extracorporeal shock wave therapy (ESWT) device, which is a non-invasive therapy [14], as it helps in the reduction of muscle tone and improves ROM, neurotransmission speed, and muscle power [15], it likewise advances cellular generation and decreases pain by creates low-energy waves and electromagnetic excitation that reason increment the regional bloodstream, neovascular changes, a decrease of inflammatory cytokines, and expanding the collagen strands and ligaments flexibility [16].

However SHS is considered one of the common reasons for chronic severe shoulder pain after stroke with hyperesthesia, swelling, and dystrophic changes in the skin of the affected UE, especially in diabetic neuropathy patients, thus the rehabilitation of hemiplegic patients is often severely affected by the development of SHS, leading to a prolonged and at times a permanent disability [17], so the purpose of this study was to investigate the influence of the MTrPs release with ESWT on SHS in stroke patients with Diabetic Peripheral Neuropathy (DPN).

\section{Subjects and methods}

Design and settings of the study

Pre- and post-experimental design study, including two equal groups, were: the study group who received MTrPs release combined with ESWT and conventional physical therapy program and the control group that received a conventional physical therapy program. This study was conducted in the outpatient clinic of the October 6 University hospital.

\section{Participants}

Thirty stroke patients were selected randomly from Neurological Department of Kasr El-Aini, and October 6 university hospital, with the following inclusion criteria: all the patients from both sexes were referred and diagnosed from a neurologist as having stroke from 4 to 8 months; with the age ranging from 45 to 60 years, body mass index (BMI) ranging from 20 to $30 \mathrm{~kg} / \mathrm{m}^{2}$, all the patients were identified with SHS as diagnosed by the Diagnostic criteria for SHS post-stroke [18] and were in stage I of syndrome evolution [19], with upper limb spasticity grades, ranging from 1 to 3 according to Modified Ashworth Scale [20] and with stage N2a mild diabetic peripheral neuropathy according to (Diabetic Neuropathy staging scale) [21] due to type II DM, while the exclusion criteria were: any other causes of shoulder pain in the side of the hemiplegia, any pain of central origin, superficial sensory loss in affected UE, impairment in mental or cognitive functions that impeded assessment and participation with treatment, structured joint deformity in the painful shoulder or hand, and any other musculoskeletal disorders of hemiparetic UE. 
The patient's consent form was read and signed before the study started, with the assurance of confidentiality and anonymity, and the performance of all the procedures complied with institutional guidelines and relevant laws. The patients were allocated equally into two groups (study and control) using the program of computer-based randomization. No dropping out of participants from the study was reported after starting the intervention (Figure 1).

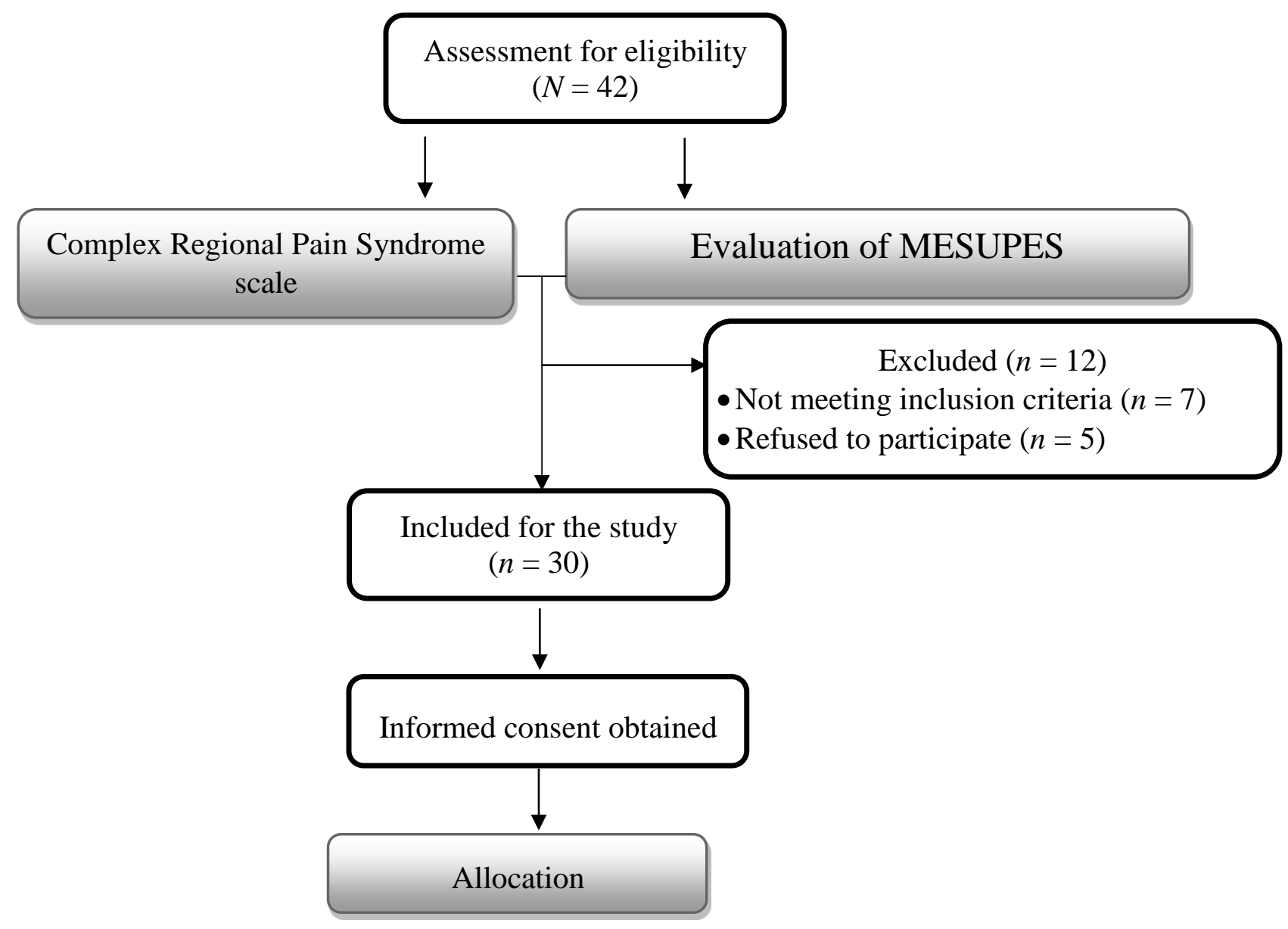

Allocated to the study group

$$
(n=15)
$$

Allocated to the control group

$$
(n=15)
$$

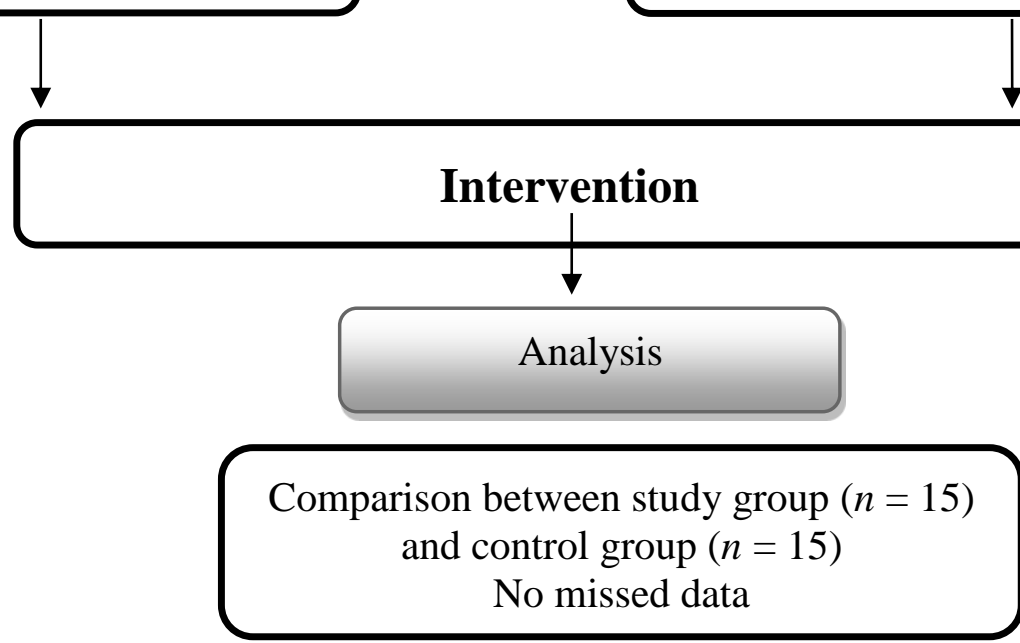

Figure 1. Flow chart showing the experimental design of the study 
- Complex Regional Pain Syndrome (CRPS) severity score

It is a quantitative index and a valid and reliable instrument to score and monitor the severity of CRPS and SHS. The CRPS Checklist included both the history and the physical assessment, as $1=$ presence and $0=$ absence for every item of 17 diagnostic CRPS signs and symptoms, the total scores ranging from 0 to 17, with the greater scores showing more CRPS severity [22].

Motor evaluation scale for upper extremity in stroke patients (MESUPES-arm, hand and all-out score)

The MESUPES evaluates the UE functional outcomes of the hemiparesis arm and hand for stroke patients. It consisted of 17 categories (all-out score/58; MESUPES-arm score/40; MESUPES-hand score/18), as the MESUPES-Arm: includes 8 items with 6 scores (0:5) as 0 scores represented the failure to adjust the muscle tone to the movement, while 5 scores represented the capacity to finish movement without help, and MESUPES-Hand: includes 9 items with 3 scores $(0: 2)$, as 3 scores as follow: $0=$ incorrect or no movement; $1=$ partial or no movement and $2=$ full movement [23]. A score of 0 was granted when the patient exhibited deficient tone, irregular muscle constrictions, mass movement patterns, or synergy (flexor/extensor). The MESUPES demonstrates a high concurrent validity in the UE motor assessment [24].

- Figure-of-Eight Method for Measuring hand swelling

The figure-of-eight technique utilizing tape measurement for hand size, as in comparison with volumetric measurements, which had a great concurrent validity and reliability [25], the measurement procedures were as follow: with the therapist assistant the forearm of the patient was pronated and extended out over the edge of the table, then the therapist started the measurement using the tape as follow: firstly the starting point of measurement was in the anatomical position of the ulnar styloid process distal part, at that point, the tape was moved over the wrist palmar surface on the radial styloid process distal part, then the tape was moved diagonally across the dorsum of the hand with the arrangement of tape on $5^{\text {th }}$ metacarpophalangeal (MCP) joint line, then the tape was moved across the palmar aspect of the MCP joints and placed on the $2^{\text {nd }}$ MCP joint, then the tape was crossed diagonally on the dorsum of the hand returning to the starting point. The hand size of the affected limb was measured in centimeters $(\mathrm{cm})$ and compared pre and post the intervention.

- Visual analogue scale for pain (VAS-P) for pain assessment

The VAS for pain is a valid and reliable assessment of pain intensity, as a straight horizontal line of a fixed length $(10 \mathrm{~cm})$ is considered the simplest VAS, the ends represented from the left the highest pain limits (worst) to the right (best). The distance was measured from the "no pain" point and the mark of the patient's on the line, giving a scope of values from 1 to $10 \mathrm{~cm}$, as a higher score represented a higher pain score [26].

\section{Intervention}

Study group: received a therapeutic intervention program including MTrP release combined with shockwave therapy and conventional physical therapy program, for four weeks; every other day, three times per week.

There were three main steps of the MTrP release technique, the initial step was to recognize and find the trigger points (TP) by the therapist palpation to detect the specific common location of each trigger point within the belly of the muscle, as each trigger point was felt as a firm and localized hyperirritable nodules. The TP for the shoulder muscles were commonly found at supraspinatus, infraspinatus, teres major, subscapularis, and pectoralis major [27-28], while for the hand muscles the TP commonly were at the pronator teres (PT), flexor carpi radialis (FCR), and flexor carpi ulnaris (FCU) [29-30]. Then the second step after TP localization and palpation was the MTrP release technique, as follow, by one or both hands, the thumbs or four fingers of the therapist applied a maintained pressure over TP and pushing internal toward the middle until a tissue restriction was felt, then the movement stopped and maintained until the restriction scattered or a "melting away" sensation of the tissue under the treating fingers, at that point, further maintained 
pressure, moving again internal to the midline as if a new tissue resistance appeared so the therapist stopped and maintained steady force against the tissue, then the therapist repeated until the inability to palpate the TP, or for five repetitions at each site. Between every TP release application, a 10second rest was given to take into consideration blood reperfusion to the site [30]. The duration for each pressure gradually increased as a 120-second hold of MFR for each muscle was given to enable the tissue to soften. The third step for powerful trigger point therapy was the myofascial stretching (MFS) exercises to keep up the relaxation and carry the muscle to its full length, with a slow prolonged stretch for each muscle that exceeded 30 seconds followed by 30 -second relaxation, with (3-5) MFS repetitions for every muscle [29].

\section{Extracorporeal Shockwave Therapy (ESWT) application}

The application of pressure pulses of ESWT was centered around the hypertonic flexor muscles of the hand inform of 3200 shots over the intrinsic muscles, flexor carpi ulnaris and radialis, and flexor digitorum tendon of the hand, using (800 for each muscle) by an ultrasound pointer [15] with energy applied $0.030 \mathrm{mj} / \mathrm{mm} 2$. Because low energy was used, the application was not painful. The patients received ESWT also on the shoulder, as the stimulation sites were the supraspinatus and subscapularis insertion sites, with the following parameters a frequency of $12 \mathrm{~Hz} /$ session, 3,000 pulses, as 1,500 pulses/site, and with the submaximal pressure between 0.39 and $1.95 \mathrm{~mJ} / \mathrm{mm} 2(1.0$ and 5.0 bar) [14]. For the stimulation at the insertion of the subscapularis, the shoulder was in lateral rotation, and $90^{\circ}$ flexed elbow, while to stimulate the insertion of the supraspinatus, the shoulder was in medial rotation and slightly extended elbow [14]. The Masterpuls MP200 (Storz Medical AG, Tagerwilen, Switzerland) was used to apply ESWT [14].

Control group: received conventional program using a selected designed physical therapy program for SHS for four weeks; every other day, three times per week, as follow: The objectives of treatment were to lessen the swelling and pain and to improve the functional recovery, therefore to reduce the swelling: a cold pack was applied around the shoulder and wrist joints for 10 minutes with gradual inspection of the skin, followed by lymphatic drainage massage of the upper extremity, then there was a program of exercises to improve the bloodstream, power and function of affected UE [18] as follow:

Passive ROM exercises were performed by the therapist as follows: lateral rotation was performed with shoulder slightly abducted, forearm supination, and for the wrist joint all passive ROM exercises were performed, the exercises stopped in point of pain, and during the next session, the therapist attempted to increase ROM past this point of pain as possible within pain limit, also flexion and extension exercises for the Metacarpophalangeal (MP) joint and interphalangeal (IP) joint of fingers and thumb were practiced. Every exercise was repeated from 5 to 10 times.

Passive and active-assisted movement by the patient: The patient utilized the non-affected UE to move the affected hand and shoulder, and at that point, the passive and active-assisted movements were encouraged as much as possible, inform of lateral rotation, elbow extension, forearm supination, and wrist joint ROM exercises. The patient also moved the MP joint and IP joint of fingers and thumb. The patient was instructed also to keep the hemiparetic UE elevated and avoid keeping the UE in a lowered position.

Neurodevelopmental approach (Bobath prolonged stretch): The intervention methods for Bobath involved the activation of key points of control for the reduction of tone that was abnormal and interferes with normal execution. Bobath prolonged stretch was applied using distal key point of control (wrist, fingers, and thumb) with a prolonged stretch between (10 or 15) minutes until tone reduction occurred as follow: the therapist performed abduction and extension of the patient's thumb and fingers, then wrist extension with forearm supination to decreases flexion tone of the wrist and fingers, then elbow extension and shoulder lateral rotation with 90 degrees abduction to decreases UE flexion tone, and at point of shoulder pain the therapist applied shoulder and scapular mobilization, then repeated the prolonged stretch again [31].

Statistical analysis

The patients' characteristics were compared between both groups using the descriptive statistics, $t$-test, and chi-square test $\left(\chi^{2}\right)$. The data normal distribution was analyzed using the Shapiro-Wilk test, and Levene's test for homogeneity of variances was performed to ensure the homogeneity 
between groups. Mixed design MANOVA was conducted to compare within and between groups effects, while for the subsequent multiple comparisons the Bonferroni correction was carried out by the Post-hoc tests. The significant level was $(p<0.05)$ for all statistical tests. The statistical methods for data collection and analysis were performed through the (SPSS) version 25 for windows (IBM SPSS, Chicago, IL, USA),

\section{Ethical approval}

The research related to human use had complied with all the relevant national regulations and institutional policies had followed the tenets of the Declaration of Helsinki, and had been approved by the Institutional Ethics Committee of the Faculty of Physical Therapy, Cairo University, Egypt (No: P.T.REC/012/002459). Agreed with the current study and the clinical trials.gov ID: NCT04627636.

\section{Informed consent}

Informed consent had been obtained from all individuals included in this study.

\section{Results}

Baseline characteristics

Comparison of the mean $(\overline{\mathrm{x}})$ values and standard deviation (SD) between both groups of patient's characteristics revealed no significant differences in age, body mass index (BMI), Duration of stroke (months), Diabetic Mellitus (DM) duration (years), mini-mental state examination (MMSE), sex, and degree of spasticity ( $p>0.05)$, as shown in (Table 1).

Table 1. Basic characteristics of all the patients

\begin{tabular}{|c|c|c|c|}
\hline & Study group & Control group & \multirow{2}{*}{$p$-value } \\
\hline & $\overline{\mathrm{X}} \pm \mathrm{SD}$ & $\overline{\mathrm{X}} \pm \mathrm{SD}$ & \\
\hline Age (years) & $56.4 \pm 3.68$ & $55.8 \pm 3.76$ & 0.66 \\
\hline BMI $\left(\mathrm{kg} / \mathrm{m}^{2}\right)$ & $26.06 \pm 0.96$ & $25.87 \pm 1.06$ & 0.59 \\
\hline Duration of stroke (months) & $5.13 \pm 0.9$ & $5.4 \pm 0.91$ & 0.43 \\
\hline DM duration (years) & $6.47 \pm 1.46$ & $7.06 \pm 1.28$ & 0.24 \\
\hline MMSE & $26.73 \pm 0.96$ & $27 \pm 1.19$ & 0.5 \\
\hline \multirow{3}{*}{$\begin{array}{l}\text { Sex } \\
\qquad \text { Male } \\
\quad \text { Female }\end{array}$} & Number (percentage) & Number (percentage) & $\begin{array}{c}\mathrm{p} \text {-value } \\
\chi^{2}\end{array}$ \\
\hline & $7(46.7 \%)$ & $6(40 \%)$ & \multirow{2}{*}{$\begin{array}{c}0.71 \\
\chi^{2}=0.13\end{array}$} \\
\hline & $8(53.3 \%)$ & $9(60 \%)$ & \\
\hline \multicolumn{3}{|l|}{ Spasticity } & \multirow{5}{*}{$\begin{array}{c}0.86 \\
\chi^{2}=0.72\end{array}$} \\
\hline Grade I & $1(6.7 \%)$ & $2(13.3 \%)$ & \\
\hline Grade I $^{+}$ & $3(20 \%)$ & $2(13.3 \%)$ & \\
\hline Grade II & $7(46.7 \%)$ & $6(40 \%)$ & \\
\hline Grade III & $4(26.6 \%)$ & $5(33.4 \%)$ & \\
\hline
\end{tabular}

BMI - body mass index, DM - diabetes mellitus, MMSE - mini-mental state examination

Effect of treatment on MESUPES-arm, MESUPES-hand, MESUPES- all-out score, Severity score of CRPS, Figure of eight test and VAS-P

Mixed MANOVA showed a significant interaction of treatment and time $\left(\mathrm{F}_{(6,23)}=62.91, p=0.001\right)$. There was a significant main effect of time $\left(\mathrm{F}_{(6,23)}=541.93, p=0.001\right)$. There was a significant main effect of treatment $\left(\mathrm{F}_{(6,23)}=9.99, p=0.001\right)$.

\section{Within-group comparison}

There was a significant increase in MESUPES-arm, MESUPES-hand, MESUPES- all-out score post-treatment in the study and control groups compared with that pre-treatment $(\mathrm{p}<0.05)$. Also, 
there was a significant decrease in severity score of CRPS, Figure of eight test and VAS-P posttreatment in the study and control groups compared with that pre-treatment $(\mathrm{p}<0.05)$ (Table 2$)$.

\section{Between groups comparison}

There was no significant difference in all parameters between both groups pre-treatment ( $\mathrm{p}>$ 0.05), while the comparison between the study and control groups post-treatment revealed a significant increase in MESUPES-arm, MESUPES-hand, MESUPES- all-out score and a significant decrease in severity score of CRPS, Figure of eight test and VAS-P of the study group compared with that of the control group $(p<0.05)$ (Table 2).

Table 2. Mean values of MESUPES-arm, MESUPES-hand, MESUPES- all-out score, Severity score of CRPS, Figure of eight test and VAS-P pre and post-treatment of the study and control groups

\begin{tabular}{|c|c|c|c|c|c|}
\hline & & \multirow{3}{*}{$\begin{array}{c}\text { Study group } \\
\overline{\mathrm{x}} \pm \mathrm{SD}\end{array}$} & \multirow{3}{*}{$\begin{array}{c}\text { Control group } \\
\overline{\bar{x}} \pm \mathrm{SD}\end{array}$} & \multirow{3}{*}{$\mathrm{MD}(95 \% \mathrm{CI})$} & \multirow{3}{*}{$p$-value } \\
\hline & & & & & \\
\hline & & & & & \\
\hline \multirow{4}{*}{ MESUPES-arm } & Pre & $17.93 \pm 3.89$ & $18.13 \pm 3.11$ & $-0.2(-2.83: 2.43)$ & 0.87 \\
\hline & Post & $34.53 \pm 3.58$ & $26.6 \pm 3.64$ & $7.93(5.23: 10.63)$ & 0.001 \\
\hline & $\operatorname{MD}(95 \% \mathrm{CI})$ & $-16.6(-18.01:-15.18)$ & $-8.46(-9.88:-7.04)$ & & \\
\hline & & $p=0.001$ & $p=0.001$ & & \\
\hline \multirow{4}{*}{ MESUPES-hand } & Pre & $8.53 \pm 1.88$ & $7.33 \pm 2.22$ & $1.2(-0.34: 2.74)$ & 0.12 \\
\hline & Post & $15.26 \pm 2.12$ & $11.4 \pm 2.67$ & 3.86 (2.06: 5.66) & 0.001 \\
\hline & $\mathrm{MD}(95 \% \mathrm{CI})$ & $-6.73(-7.55:-5.91)$ & $-4.06(-4.89:-3.24)$ & & \\
\hline & & $p=0.001$ & $p=0.001$ & & \\
\hline \multirow{4}{*}{$\begin{array}{l}\text { MESUPES- all- } \\
\text { out score }\end{array}$} & Pre & $25.8 \pm 3.5$ & $25.46 \pm 4.47$ & $0.34(-2.67: 3.33)$ & 0.82 \\
\hline & Post & $49.8 \pm 4.01$ & $37.33 \pm 6.84$ & $12.47(8.27: 16.65)$ & 0.001 \\
\hline & $\mathrm{MD}(95 \% \mathrm{CI})$ & $-24(-26.21:-21.78)$ & $-11.86(-14.07:-9.65)$ & & \\
\hline & & $p=0.001$ & $p=0.001$ & & \\
\hline \multirow{4}{*}{$\begin{array}{l}\text { Severity score of } \\
\text { CRPS }\end{array}$} & Pre & $12.53 \pm 1.13$ & $12.73 \pm 0.88$ & $-0.2(-0.95: 0.55)$ & 0.59 \\
\hline & Post & $6.33 \pm 1.58$ & $9.26 \pm 1.22$ & $-2.93(-3.99:-1.87)$ & 0.001 \\
\hline & $\mathrm{MD}(95 \% \mathrm{CI})$ & $6.2(5.7: 6.69)$ & $3.46(2.97: 3.95)$ & & \\
\hline & & $p=0.001$ & $p=0.001$ & & \\
\hline \multirow{4}{*}{$\begin{array}{l}\text { Figure of eight } \\
\text { test }(\mathrm{cm})\end{array}$} & Pre & $45.13 \pm 2.07$ & $45.57 \pm 1.6$ & $-0.44(-1.81: 0.94)$ & 0.52 \\
\hline & Post & $39.5 \pm 1.95$ & $42.27 \pm 2.31$ & $-2.77(-4.36:-1.16)$ & 0.001 \\
\hline & $\operatorname{MD}(95 \% \mathrm{CI})$ & $5.63(4.45: 6.8)$ & $3.3(2.12: 4.47)$ & & \\
\hline & & $p=0.001$ & $p=0.001$ & & \\
\hline \multirow{4}{*}{ VAS-P (cm) } & Pre & $8.06 \pm 0.79$ & $8.13 \pm 1.06$ & $-0.07(-0.76: 0.63)$ & 0.84 \\
\hline & Post & $3.13 \pm 0.83$ & $6.06 \pm 1.09$ & $-2.93(-3.66:-2.2)$ & 0.001 \\
\hline & $\mathrm{MD}(95 \% \mathrm{CI})$ & $4.93(4.44: 5.42)$ & $2.06(1.57: 2.56)$ & & \\
\hline & & $p=0.001$ & $p=0.001$ & & \\
\hline
\end{tabular}

MESUPES - motor evaluation scale for upper extremity in stroke, CRPS - complex regional pain syndrome, VAS-P - visual analogue scale for pain

Correlation between motor function and pain levels

Pearson Correlation Coefficient was conducted to determine the correlation between UE motor function, and pain, across the two groups post-treatment. The correlation between MESUPES- allout score and VAS-P was a moderate negative significant correlation with $r$ value $=-0.61$ and $p$ value $=0.0001$.

\section{Discussion}

The main objective of the present study was to investigate the influence of MTrPs release combined with shockwave therapy on pain and functions of UE with SHS in thirty stroke patients with DPN. All the patients were diagnosed via MESUPES, CRPS scale, the figure of eight test, and VAS- pain scores, and the findings showed that there was a highly significant improvement of UE functions, with a significant reduction in SHS symptoms, hand swelling, and pain level of the study group compared to the control group.

Together these results were in agreement with a previous study that showed that after MTrPs release of the shoulder in stroke patients, the patients presented with significantly lower pain levels 
and a larger ROM for passive abduction [11], also another study stated that in stroke patients, the prevalence of MTrPs release was high, so its examination and treatment were important, as the outcomes demonstrated that the highest incidence of active MTrPs had a rate of infraspinatus 50\%, supraspinatus $34 \%$, upper trapezius $20 \%$ and teres minor $12 \%$, and there was a moderate correlation between the measurements of UE dysfunctions using the DASH and MTrPs in infraspinatus and active MTrPs of the supraspinatus [32].

The impact of MTrPs release for UE of stroke patients in a previous study utilizing by dry needling which had the same qualities of manual MTrPs release, the results approved that the MTrPs release using dry needling for the infraspinatus, teres major, teres minor, and pectoralis major could immediately increase shoulder passive ROM, so the MTrPs release considered a highly effective technique during the early rehabilitation of hemiparetic shoulder pain syndrome [28], as it also diminished the spastic muscles of UE and increased the function of UE in stroke. The findings of the current study supported also by Bron et al. [33] who surveyed the adequacy of MTrPs release in patients with chronic pain at shoulder, by manual pressure of the MTrPs followed by MFS, as the outcomes showed decreasing the questionnaire scores of Disabilities of the Arm, Shoulder, and Hand functions (DASH) and also reduction of VAS-P scores.

Because of the contracted tight band of MTrPs, the motor dysfunctions represent, hence the painful affected muscles around the shoulder girdle may represent a weakness of the involved muscles and limited ROM in the shoulder joint [34] that also may affect the position of the scapula and leads to scapular malpositioning and dyskinesia in stroke patients [35]. The examination of the suitability of MTrPs release for shoulder muscles in patients with chronic shoulder pain of myofascial origin was investigated in previous research and the outcomes demonstrated a significant reduction in the pain of the shoulder and scores of dysfunction index [36]. In the current study, Myofascial Passive stretching showed improvement in UE functions outcomes scores for MESUPES as it was directed at stretching the over-shortened and spastic muscle fibers, as it involved slow prolonged stretch with suitable concentration and relaxation that inhibit the gamma spindle response [37], hence Myofascial Passive stretching involves stretching the muscle as far as possible for nearly 45 seconds of maintenance until the relaxation of the muscle, also stimulates the Golgi tendon organs that results in a reflex relaxation of the muscle within 60 seconds of static or prolonged stretches, for enabling the muscle to stretch through relaxation before reaching the extensibility limits [37].

Therefore the findings of the present study showed that the SHS in stroke patients was related to constrained ROM of the shoulder, this was believed to be because of both capsular fibrosis and synovial inflammation, which could be disturbed due to, loss of motion, spasticity, paralysis, or synergy of movements, leading to pain and decrease shoulder movement [38]. The ESWT that used in the current study resulted in a reduction in VAS- pain scores and improvement of UE functions of stroke patients with DPN that was in agreement with Kim et al. [14] who investigated the impact of ESWT on hemiplegic shoulder pain (HSP) syndrome on the insertion sites of subscapularis and supraspinatus, as the results showed that the VAS score, and the shoulder joint ROM, including medial and lateral rotation, flexion and abduction, were fundamentally improved post-intervention. The pain reduction after ESWT lasted for at least 4 weeks, while the ESWT immediate pain reduction followed application can be clarified by the after-effect of a hyperstimulation painrelieving impact [14]. In previous research that recognized the impacts of ESWT on motor skills and mechanical properties of muscles in stroke patients, the findings affirmed a significant decrease in muscle tone post ESWT intervention in patients with spastic hemiplegia as the ESWT is considered to diminish the hypertonia of spastic muscles in stroke patients by changing the rheological properties of thixotropic tissues, where fibrosis was diminished and veins were improved [15]. The ESWT also had a great effect in patients with diabetic frozen shoulder, as showed in the findings of previous research which approved that the ESWT could lead to an improvement in the functional outcomes and ROM of the shoulder joint and could reduce the shoulder pain in diabetic patients [39], also other study showed that the ESWT was effective on reducing shoulder disability index, improving ROM, and reducing pain severity in the painful shoulder in patients with DPN [40]. However, the improvement of SHS symptoms in stroke patients who received a conventional program including cold application, lymphatic drainage, and ROM exercises [18], could be due to improve circulation and enhance UE function, hence, the selection of the suitable treatment method at a specified stage of recovery varies among stroke patients [41]. For 
future studies, it would be beneficial to assess the effect of MTrPs release in stroke without diabetic neuropathy, on other trigger points, on other causes of shoulder pain, and sensorimotor functions of the hemiparetic upper extremity.

\section{Conclusion}

The Myofascial Trigger Points release combined with shockwave therapy had a great impact on SHS in stroke patients with diabetic neuropathy, as the findings showed a significant reduction in SHS symptoms including pain and swelling, and also improvement in the level of upper extremity functions, thus both the MTrPs release and ESWT application should be considered as a potential rehabilitation program in stroke patients with SHS.

\section{Conflict of interest}

The authors state no conflict of interest.

\section{Disclosure statement}

No author had any financial interest or received any financial benefit from this research.

\section{References}

1. Adey-Wakeling Z, Arima H, Crotty M, Leyden J, Kleinig T, Anderson CS, Newbury J, SEARCH Study Collaborative. Incidence and associations of hemiplegic shoulder pain poststroke: prospective population-based study. Arch Phys Med Rehabil. 2015;96(2):241-247; doi: 10.1016/j.apmr.2014.09.007.

2. Liu S, Zhang C, Cai Y, Guo X, Zhang A, Xue C, Lu C. Acupuncture for post-stroke shoulderhand syndrome: a systematic review and meta-analysis. Front Neurol. 2019;(10):433; doi: 10.3389/fneur.2019.00433.

3. Kocabas H, Levendoglu F, Ozerbil OM, Yuruten B. Complex regional pain syndrome in stroke patients. Int J Rehabil Res. 2007; 30(1):33-8. https://doi: 10.1097/MRR.0b013e3280146f57.

4. Sebastin SJ. Complex regional pain syndrome. Indian J Plastic Surg. 2011;44(2):298-307; https://doi: 10.4103/0970-0358.85351

5. Kim YW, Kim Y, Kim JM, Hong JS, Lim HS, Kim HS. Is poststroke complex regional pain syndrome the combination of shoulder pain and soft tissue injury of the wrist?: A prospective observational study: STROBE of ultrasonographic findings in complex regional pain syndrome. Medicine 2016; 95(31):e4388; doi: 10.1097/MD.0000000000004388.

6. Vahdatpour B, Taheri P, Zade AZ, Moradian S. Efficacy of extracorporeal shockwave therapy in frozen shoulder. Int J Prev Med. 2014;5(7):875-881.

7. Hannan MA, Sabeka MM, Miah MBA. Shoulder hand syndrome in hemispheric stroke.JNeurolSci.2013;333(1):e167; doi: 10.1016/j.jns.2013.07.693.

8. Miller W. Maxwell A, Q. C. Nguyen V. Management of Hemiplegic Shoulder Pain. Curr Phys Med Rehabil Rep. 2013;1(1); doi:10.1007/s40141-012-0001-y.

9. Wyatt LH, Ferrance RJ. The musculoskeletal effects of diabetes mellitus. J Can Chiropr Assoc. 2006;50(1):43-50

10. Choi JH, Yu KP, Yoon Y-S, Kim ES, Jeon JH. Relationship between HbA1c and complex regional pain syndrome in stroke patients with type 2 diabetes mellitus. Ann Rehabil Med. 2016;40(5):779-785; doi: 10.5535/arm.2016.40.5.779.

11. Liporaci FM, Mourani MM, Riberto M. The myofascial component of the pain in the painful shoulder of the hemiplegic patient. Clinics (Sao Paulo). 2019;74 e905; doi: 10.6061/clinics/2019/e905.

12. Duncan B, McDonough-Means S, Worden K, Schnyer R, Andrews J, Meaney FJ. Effectiveness of osteopathy in the cranial field and myofascial release versus acupuncture as complementary treatment for children with spastic cerebral palsy: a pilot study. J Am Osteopath Assoc. 2008;108(10):559-570

13. Shah S, Bhalara A. Myofascial release. Int J Health Sci Res. 2012;2(2):69-77.

14. Kim SH, Ha KW, Kim YH, Seol P-H, Kwak H-J, Park S-W, Ryu B-J. Effect of radial extracorporeal shock wave therapy on hemiplegic shoulder pain syndrome. Ann Rehabil Med. 2016;40(3):509-519; doi: 10.5535/arm.2016.40.3.509 
15. Park SK, Yang DJ, Uhm YH, Yoon JH, Kim JH. Effects of extracorporeal shock wave therapy on upper extremity muscle tone in chronic stroke patients. J Phys Ther Sci. 2018;30(3):361364; doi:10.1589/jpts.30.361.

16. Adel S, Elazm S, Abdel-Raoof N, Khaled A. Shock wave therapy versus phonophoresis in treatment of diabetic frozen shoulder. Biosci Res. 2019;16(1):733-740.

17. Harden RN, Bruehl SP. Diagnosis of complex regional pain syndrome: signs, symptoms, and new empirically derived diagnostic criteria. Clin J Pain. 2006;22(5):415-419.

18. Kondo I, Hosokawa K, Soma M, Iwata M, Maltais D. Protocol to prevent shoulder-hand syndrome after stroke. Arch Phys Med Rehabil. 2001;82(11):1619-1623.

19. Kozin F, Ryan LM, Carerra GF, Soin JS, Wortmann RL. The reflex sympathetic dystrophy syndrome (RSDS): III. Scintigraphic studies, further evidence for the therapeutic efficacy of systemic corticosteroids, and proposed diagnostic criteria. Am J Med. 1981;70(1):23-30.

20. Meseguer-Henarejos A-B, Sanchez-Meca J, Lopez-Pina J-A, Carles-Hernandez R. Inter-and intra-rater reliability of the Modified Ashworth Scale: a systematic review and meta-analysis. Eur J Phys Rehabil Med. 2018;54(4):576-590; doi: 10.23736/S1973-9087.17.04796-7.

21. Wwlyn JG Tomlinson DR TPKDPJTPK. Diabetic Neuropathies in Peripheral Neuropathy. Philadelphia: Elsevier Saunders 2005;2 4th Ed..

22. Harden RN, Bruehl S, Perez RSGM, Birklein F, Marinus J, Maihofner C, Lubenow T, Buvanendran A, Mackey S, Graciosa J, Mogilevski M, Ramsden C, Schlereth T, Chont M, Vatine JJ. Development of a severity score for CRPS. Pain. 2010;151(3):870-6.

23. Johansson GM, Häger CK. Measurement properties of the motor evaluation scale for upper extremity in stroke patients (MESUPES). Disability and Disabil Rehabil. 2012;34(4):288-94.

24. Van de Winckel A1, Feys H, van der Knaap S, Messerli R, Baronti F, Lehmann R, Van Hemelrijk B, Pantè F, Perfetti C, De Weerdt W. Can quality of movement be measured? Rasch analysis and inter-rater reliability of the Motor Evaluation Scale for Upper Extremity in Stroke Patients (MESUPES). Clin Rehabil. 2006;20(10):871-84.

25. Leard JS, Breglio L, Fraga L, Ellrod N, Nadler L, Yasso M, Fay E, Ryan K, Pellecchia GL. Reliability and concurrent validity of the figure-of-eight method of measuring hand size in patients with hand pathology. J Orthop Sports Phys Ther. 2004;34(6):335-40.

26. Bourdel N, Alves J, Pickering G, Ramilo I, Roman H, Canis M. Systematic review of endometriosis pain assessment: how to choose a scale? Hum Reprod Update. 2015;21(1):13652 .

27. Mendigutia-Gómez A, Martin-Hernández C, Salom-Moreno J, Fernández-de-las-Peñas C. Effect of dry needling on spasticity, shoulder range of motion, and pressure pain sensitivity in patients with stroke: a crossover study. J Manipulative Physiol Ther. 2016;39(5):348-358. http://doi:10.1016/j.jmpt.2016.04.006.

28. Tang L, Li Y, Huang Q-M, Yang Y. Dry needling at myofascial trigger points mitigates chronic post-stroke shoulder spasticity. Neural Regen Res. 2018;13(4):673-676.http:// doi:10.4103/1673-5374.230293.

29. Kostopoulos D, Rizopoulos K. the manual of trigger point and myofascial therapy. Astoria, New York, Chap. 2001;10:14-64.

30. Moraska AF, Schmiege SJ, Mann JD, Butryn N, Krutsch JP. Responsiveness of Myofascial Trigger Points to Single and Multiple Trigger Point Release Massages: A Randomized, Placebo Controlled Trial. Am J Phys Med Rehabil. 2017;96(9):639-645; doi: 10.1097/PHM.0000000000000728.

31. Mepsted R, Tyson S. The Bobath concept. A guru-led set of teachings unsupported by emerging evidence. A response to Vaughan-Graham and Cott $\mathrm{J}$ Eval Clin Pract. 2017;23(5):1127-1128.

32. Villafañe JH, Lopez-Royo MP, Herrero P, Valdes K, Cantero-Téllez R, Pedersini P, Negrini S. Prevalence of myofascial trigger points in poststroke patients with painful shoulders: a crosssectional study. PM R. 2019;11(10):1077-1082.

33. Bron C, De Gast A, Dommerholt J, Stegenga B, Wensing M, Oostendorp RAB. Treatment of myofascial trigger points in patients with chronic shoulder pain: a randomized, controlled trial. BMC Med. 2011;9:8; doi: 10.1186/1741-7015-9-8.

34. Falla D, Farina D, Graven-Nielsen T. Experimental muscle pain results in reorganization of coordination among trapezius muscle subdivisions during repetitive shoulder flexion. Exp 
Brain Res. 2007;178:385-93; doi: 10.1007/s00221-006-0746-6.

35. Mahmoud, L.S.ED., Aly, S.M. The effect of scapular dyskinesia on the scapular balance angle and upper extremity sensorimotor function in stroke patients with spasticity. Bull Fac Phys Ther. 2020;25(1):1-8; doi: 10.1186/s43161-020-00004-w.

36. Hains G, Descarreaux M, Hains F. Chronic shoulder pain of myofascial origin: a randomized clinical trial using ischemic compression therapy. J Manipulative Physiol Ther. 2010;33(5):362-9; doi: 10.1016/j.jmpt.2010.05.003.

37. Pawaria S, Kalra S. Comparing effectiveness of myofascial release and muscle stretching on pain, disability and cervical range of motion in patients with trapezius myofascial trigger points. Indian J Health Sci Care. 2015;2(1):8-13; doi: 10.5958/2394-2800.2015.00002.4.

38. Neviaser A, Neviaser R. Adhesive capsulitis of the shoulder. J Am Acad Orthop Surg. 2011;19(9):536-42.

39. Mohamed K. Seyam Ezzat E. Moubarak ARS. The Effect of extracorporeal shock wave therapy for patients with diabetic frozen shoulder. Ajmaah J Health Sci. 2018;6(2):40-49.

40. Santoboni F, Balducci S, D'Errico V, Haxhi J, Vetrano M, Piccinini G, Ferretti A, Pugliese G, Vulpiani MC. Extracorporeal shockwave therapy improves functional outcomes of adhesive capsulitis of the shoulder in patients with diabetes; Diabetes Care. 2017;40(2):12-13; doi: 10.2337/dc16-2063.

41. Abba MA, Muhammad AS, Badaru UM, Abdullahi A. Comparative effect of constraintinduced movement therapy and proprioceptive neuromuscular facilitation on upper limb function of chronic stroke survivors. Physiother Quart. 2020;28(1):1-5; doi:10.5114/pq.2020.89809 